\title{
The FAO/WHO International Food Safety Authorities Network in Review, 2004-2018: Learning from the Past and Looking to the Future
}

\author{
Carmen Joseph Savelli,, ${ }^{1,2}$ Adam Bradshaw, ${ }^{1}$ Peter Ben Embarek, ${ }^{1}$ and Céu Mateus ${ }^{2}$
}

\begin{abstract}
Contemporary patterns of global food trade necessitate cross-border communication between government authorities when unsafe food enters international commerce. The Food and Agriculture Organization of the United Nations (FAO)/World Health Organization (WHO) International Food Safety Authorities Network (INFOSAN), established in 2004, facilitates urgent communication between >600 members from 188 of the 194 FAO and WHO Member States around the world and supports the strengthening of food safety systems in an effort to mitigate the global burden of foodborne disease. For nearly 15 years, INFOSAN has been operating as a global, virtual community of practice $(\mathrm{CoP})$, fostering knowledge transfer and exchange between members, and enabling crucial international communication during food safety emergencies. During this time, a number of important partnerships have been forged, including with other networks like PulseNet International. Complementarity, and cooperation between global networks like INFOSAN and PulseNet is vital to improve the efficiency and effectiveness of global efforts to curb foodborne illness. Since 2011, detailed data related to the patterns of information exchange during 293 food safety emergencies communicated through INFOSAN have been documented systematically. An analysis of these data reveals that a relatively limited number of active members from a select group of Member States contribute the majority of information exchanged through the network. For example, nine (5\%) Member States were each involved in 24 or more food safety events communicated through INFOSAN between 2011 and 2017, whereas 123 (65\%) Member States were involved in three events or less, including $36(19 \%)$ involved in none. These data also demonstrate that although the overall responsiveness of members during emergencies has improved in recent years, impediments to rapid and efficient information sharing still persist. A number of potential barriers to active participation in INFOSAN have been hypothesized, but members themselves have not been conferred with on their relative importance. As a member-driven network, future research to investigate the experiences of INFOSAN members in a rigorous and systematic manner is recommended. Such work could illuminate the specific areas in which to introduce operational shifts by the INFOSAN Secretariat, to strengthen the global CoP, increase the value of INFOSAN among members, and have a robust and meaningful impact at country level to reduce the burden of foodborne disease globally.
\end{abstract}

Keywords: food safety, foodborne illness, international networks, communication, emergency response, community of practice, INFOSAN, World Health Organization, Food and Agriculture Organization of the United Nations

\footnotetext{
${ }^{1}$ Department of Food Safety and Zoonoses, World Health Organization, Geneva, Switzerland.

${ }^{2}$ Faculty of Health and Medicine, Division of Health Research, Lancaster University, Lancaster, United Kingdom.

The authors alone are responsible for the views expressed in this article and they do not necessarily represent the views, decisions, or policies of the institutions with which they are affiliated.

(C) Carmen Joseph Savelli et al. 2019; Published by Mary Ann Liebert, Inc. This Open Access article is distributed under the terms of the Creative Commons Attribution Noncommercial License (http://creativecommons.org/licenses/by-nc/4.0/) which permits any noncommercial use, distribution, and reproduction in any medium, provided the original author(s) and the source are cited.
} 


\section{Introduction}

$\mathbf{I}^{\mathrm{N}}$ N 2015, the World Health Organization (WHO) reported estimates of the global burden of foodborne diseases for the first time. Together, 31 foodborne hazards are estimated to cause 600 million cases of foodborne disease and 420,000 deaths annually, worldwide (WHO, 2015). Foodborne diseases are preventable, but ensuring a safe national food supply requires a robust food control system and coordination among different government sectors responsible for human health, animal health, agriculture, trade, and others. In addition, as a global commodity, contaminated food in one country can readily cause international outbreaks if distributed internationally.

Channels of communication on matters of food safety must therefore be well established within and between countries to facilitate efficient food recalls or outbreak investigations and prevent national and international food safety emergencies (WHO, 2014). It is for these reasons why the WHO launched the International Food Safety Authorities Network (INFOSAN) in 2004, in cooperation with the Food and Agriculture Organization (FAO) of the United Nations. Today, INFOSAN operates with an overall goal to halt the international spread of contaminated food, prevent foodborne disease outbreaks, and strengthen food safety systems globally (FAO/WHO, 2016a).

This article provides an overview of INFOSAN that includes a brief history and description of the general activities undertaken by the network. It also serves to orient INFOSAN as a community of practice $(\mathrm{CoP})$, which facilitates urgent international communication during food safety emergencies and functions as a platform for knowledge transfer and exchange (KTE) among its global membership.

In addition, an analysis of the communication activities undertaken through INFOSAN during food safety emergencies is presented with a view to demonstrate the responsiveness of members during such events and to recognize patterns of activity. This analysis can serve as a baseline for further research into the experiences of INFOSAN members, with an aim to improve their engagement. Potential barriers to active participation in INFOSAN are presented and recommendations for future research are provided. Overall, the essential role of INFOSAN as a global tool to improve food safety and mitigate the burden of foodborne disease is illuminated.

\section{History and Current Status}

The stimulus for the creation of a global network of food safety authorities originated directly from Member States' requests. In 2000, a resolution was adopted at the WHO World Health Assembly (WHA), calling for improved communication between WHO and Member States on matters of food safety. Specifically, Member States requested that WHO respond immediately to international food safety emergencies and assist countries with crisis management (WHO, 2000). Two years later, serious concerns were expressed at the WHA with respect to health emergencies posed by natural, accidental, and intentional contamination of food and Member States again reiterated the important need for international coordination on matters of food safety (WHO, 2002).

Later in 2002, recommendations for the establishment of a government level, international food safety network resulted from a series of international conferences, including the
FAO/WHO Global Forum for Food Safety Regulators (FAO/WHO, 2002a) and the FAO/WHO Pan-European Conference on Food Safety and Quality (FAO/WHO, 2002b). Subsequently in 2003, WHO published a report on potential terrorist threats to food, which includes guidance for establishing and strengthening prevention and response systems and identifies an international food safety emergency network as one of the basic measures of preparedness needed at the global level (WHO, 2003).

Following this in 2004, the Codex Alimentarius Commission (CAC) revised the "Principles and Guidelines for the Exchange of Information in Food Safety Emergency Situations (CAC/GL 19-1995)," introducing the recommendation that Member States should designate official points of contact from their respective food safety authorities to exchange information during international food safety emergencies (FAO/WHO, 2004a). The revised guidelines also indicated that WHO should be responsible for keeping an updated list of these official points of contact. In response to a clear need, expressed prominently and repeatedly in multiple global fora, the WHO officially launched INFOSAN in 2004, in cooperation with FAO, at the FAO/WHO Second Global Forum for Food Safety Regulators (FAO/WHO, 2004b).

Upon launching, members around the world began to utilize INFOSAN to exchange information during international food safety events. Important to note is that the INFOSAN Secretariat only shares details about food safety events that have been first validated by INFOSAN members (i.e., national government authorities), to ensure the information disseminated through the network is reliable. Within a few years, major events like the 2008 Melamine incident (300,000 infants and children became ill in China, 6 of whom died, as a result of consuming milk products contaminated with melamine) brought renewed attention to the importance of INFOSAN because contaminated products were directly exported or secondarily distributed to 47 countries around the world (Gossner et al., 2009).

Shortly thereafter in 2010, a resolution on Advancing Food Safety Initiatives was adopted at the WHA, reemphasizing the important role of INFOSAN and reinforcing its global mandate. A few years later in 2014, at the second International Conference on Nutrition (ICN2), the importance of exchanging food safety information between government authorities nationally and across borders to prevent foodborne diseases was underscored. As an outcome, it was recommended that Member States actively participate in INFOSAN, especially during food safety emergencies (FAO/WHO, 2014).

In 2016, in recognition of the growth and development of INFOSAN, the CAC once again revised the "Principles and Guidelines for the Exchange of Information in Food Safety Emergency Situations (CAC/GL 19-1995),' by making appropriate references to INFOSAN (FAO/WHO, 2016b). This important revision, endorsed by all CAC members, has further solidified the global mandate of INFOSAN and the important and internationally recognized role that INFOSAN should play in the rapid exchange of information between countries during food safety emergencies.

In addition, since the International Health Regulations (IHR [2005]), came into force in 2007, INFOSAN has been recognized as a fundamental tool to assist countries in developing the core capacities required for food safety emergency preparedness and response (WHO, 2018a). Recently, 
INFOSAN has demonstrated its utility during two major food safety emergencies that captured global media headlines for months in 2017 and 2018, including an outbreak of salmonellosis in France linked to domestically produced infant formula that was exported to more than 80 countries ( 37 cases reported) and an outbreak of listeriosis in South Africa linked to domestically produced ready-to-eat meat products that were exported to 15 countries (1060 cases and 216 deaths reported in South Africa).

During both these events, the INFOSAN Secretariat relied on the swift action of national INFOSAN Emergency Contact Points to respond to requests for information. The INFOSAN Secretariat was subsequently able to rapidly notify INFOSAN members in importing countries of the details of the recalled products to stop their distribution, and allow competent authorities around the world to implement appropriate risk management measures to prevent additional cases of illness (WHO, 2018b).

When it was launched, INFOSAN included members from $\sim 100$ Member States. In 2018, that number has grown to 188/194 (97\%) Member States with >600 individual members from a range of national authorities from various sectors involved in food safety management (health, agriculture, trade, environment, standards, etc.). To join the network, Member States have designated, by official letter to the INFOSAN Secretariat, one Emergency Contact Point from the authority responsible for national coordination of food safety emergency response activities. Additional Focal Points from different national authorities have also been designated in many Member States in recognition of the multidisciplinary nature of food safety management.

Today, INFOSAN members have a common identity that is defined by their shared interest in the food safety domain. By joining the network, each has committed to taking actions that contribute to a safer global food supply by engaging in joint activities and discussions to facilitate KTE among members. Common responsibilities are also shared by members, as defined by the INFOSAN Secretariat.

Combined, these common responsibilities and activities create a sense of community, and are undertaken with the intention of facilitating the application of best practices to improve food safety. In addition, INFOSAN members are each practitioners in their respective countries, as food regulators, risk analysts, epidemiologists, or another type of food safety or public health professional. Although each member's focus may be different, the uniting factor is that their practice, in some respect, aims to reduce foodborne illness.

It is the shared domain, community, and practice that allows for INFOSAN to be understood as a CoP (Wenger et al., 2002). A CoP is a group of people sharing a particular concern, problem, or passion for an area and who deepen their knowledge and expertise by learning from one another and interacting on a regular basis (Wenger et al., 2002). Such interactions may occur in person or through technologymediated means, as with INFOSAN, which utilizes the INFOSAN Community Website (ICW), launched in 2012, to facilitate communication and KTE. The ICW is a secure, online portal that allows INFOSAN members from around the world to exchange information on urgent food safety events and emerging trends of potential global interest.

The ICW provides a virtual environment with a multilingual (English, French, and Spanish) user interface to share lessons learnt and allows members to pose questions to one another for the purpose of exchanging knowledge related to food safety (FAO/WHO, 2016a).

\section{Interactions with Other Networks}

On a biannual basis, the INFOSAN Secretariat delivers a workplan that serves to strengthen the global CoP of INFOSAN members and improve their abilities to respond effectively during international food safety events. To achieve this, the workplan has most recently focused on three key areas, including (1) emergency response activities; (2) communication activities; and (3) national capacity-building activities. Much of this work is carried out in close collaboration with several important regional and global partners and networks.

At the regional level, the INFOSAN Secretariat collaborates closely with colleagues from the European Commission (EC), for example, to ensure complementarity between the EC Rapid Alert System for Food and Feed (RASFF) and INFOSAN. One way in which this has been achieved is through the designation of all national RASFF Contact Points as INFOSAN members, preventing parallel and redundant communication channels during emergency communications. Updated working instructions for RASFF members detail the way in which the INFOSAN Secretariat is notified on a daily basis of all serious risks identified through RASFF that involve countries outside Europe (European Commission, 2017). These notifications allow the INFOSAN Secretariat to follow-up with INFOSAN members beyond the EU border to ensure that appropriate risk management measures are implemented around the world.

PulseNet International is an example of a global network with which INFOSAN has forged another important collaboration. PulseNet International is a well-established network that builds capacity for the molecular surveillance of foodborne disease, outbreak detection, and response worldwide (Nadon et al., 2017). Information generated by PulseNet International can be critical in linking international outbreaks of concern to members of INFOSAN and has been the source of such information during dozens of food safety events communicated through INFOSAN.

In many cases, PulseNet International has been the first to share signals with the INFOSAN Secretariat that indicate a food safety event has international implications, including during an outbreak of salmonellosis in Canada and the United States that was caused by internationally distributed chia seed products in 2014 (FAO/WHO, 2016a). In such instances, the swift sharing of information by PulseNet International enables the INFOSAN Secretariat to follow-up with affected Member States and ensures appropriate risk management measures are implemented.

During several events communicated through INFOSAN, PulseNet International has also demonstrated the utility of whole-genome sequencing to link outbreaks to the source of infection faster than would have been possible using other methods, including during an outbreak of listeriosis linked to internationally distributed prepackaged caramel apples in 2014 (FAO/WHO, 2016a). This event was the first one for which the INFOSAN Secretariat included the wholegenome sequence of the outbreak strain in communication to INFOSAN members to aid national authorities in identifying related cases in their respective countries. Since then, 
Table 1. Number of Member States Involved in Food Safety Events Communicated Through the International Food Safety Authorities Network, by Region, 2011-2017

\begin{tabular}{|c|c|c|c|c|c|c|c|c|}
\hline Region (No. of $M S$ ) & $\begin{array}{l}2011 \\
\text { n }(\%)\end{array}$ & $\begin{array}{l}2012 \\
\text { n }(\%)\end{array}$ & $\begin{array}{l}2013 \\
\text { n }(\%)\end{array}$ & $\begin{array}{l}2014 \\
\text { n }(\%)\end{array}$ & $\begin{array}{l}2015 \\
\text { n }(\%)\end{array}$ & $\begin{array}{l}2016 \\
\mathrm{n}(\%)\end{array}$ & $\begin{array}{l}2017 \\
\text { n }(\%)\end{array}$ & $\begin{array}{c}\text { All years } \\
\mathrm{n}(\%)\end{array}$ \\
\hline Africa (47) & $2(4)$ & $5(11)$ & 0 & $5(11)$ & $11(23)$ & $8(17)$ & $40(85)$ & $41(87)$ \\
\hline Americas (35) & $10(29)$ & $10(29)$ & $13(37)$ & $15(43)$ & $17(49)$ & $9(26)$ & $13(37)$ & $27(77)$ \\
\hline Eastern Mediterranean (21) & $5(23)$ & $2(10)$ & $7(33)$ & 4 (19) & $11(52)$ & $11(52)$ & $18(86)$ & $20(95)$ \\
\hline Europe (53) & $27(51)$ & $30(57)$ & $39(74)$ & $28(53)$ & $23(43)$ & $20(38)$ & $32(60)$ & $46(87)$ \\
\hline South-East Asia (11) & $3(27)$ & $4(36)$ & $5(45)$ & $4(36)$ & $5(45)$ & $6(55)$ & $6(55)$ & $9(82)$ \\
\hline Western Pacific (27) & $9(33)$ & $10(37)$ & $11(41)$ & $10(37)$ & $10(37)$ & $9(33)$ & $11(41)$ & $16(59)$ \\
\hline All regions (194) & $56(29)$ & $61(31)$ & $75(39)$ & $66(34)$ & $77(40)$ & $63(32)$ & $120(62)$ & $159(82)$ \\
\hline
\end{tabular}

MS, Member States.

INFOSAN has been and continues to be, a platform through which to transfer knowledge and educate members on the utility of whole-genome sequencing technology for food safety (Nanyang Technological University, 2016).

Strengthening partnerships with other networks and initiatives is a strategic priority for the INFOSAN Secretariat to ensure complementarity and optimize efforts to achieve common goals with respect to mitigating the global burden of foodborne disease. There is an abundance of regional networks and initiatives at various stages of development and utility that relate to the exchange of food safety information during emergencies in select regions. The global food safety community would benefit from a thorough mapping of the interlinkages between such networks to better understand how they are being used, by whom, and in what contexts.

\section{Emergency Network Activities (2011-2017)}

During food safety events, the INFOSAN Secretariat supports information exchange between members, enabling risk management measures to be implemented to prevent foodborne illness. The level of engagement by the INFOSAN Secretariat in each food safety event varies depending on a number of factors, including the countries involved, the severity of the public health impact, and the duration of the event.

In some cases, the INFOSAN Secretariat plays a facilitating role, ensuring that affected members have access to each other's contact details. In other cases the INFOSAN Secretariat provides technical advice or information to an INFOSAN member regarding a food safety event or issue. During complex events involving multiple countries, the INFOSAN Secretariat actively obtains and disseminates information to and from INFOSAN members regarding food safety events of international concern and enabling risk management measures to be implemented, such as recalls, public alerts, and risk communication with consumers.

During such events, the INFOSAN Secretariat also collects information about illnesses in different countries that may be linked to the same food source, as well as the results of traceback activities and root-cause analyses. This information is then summarized on the ICW. The details related to such food safety emergencies reported through INFOSAN have been

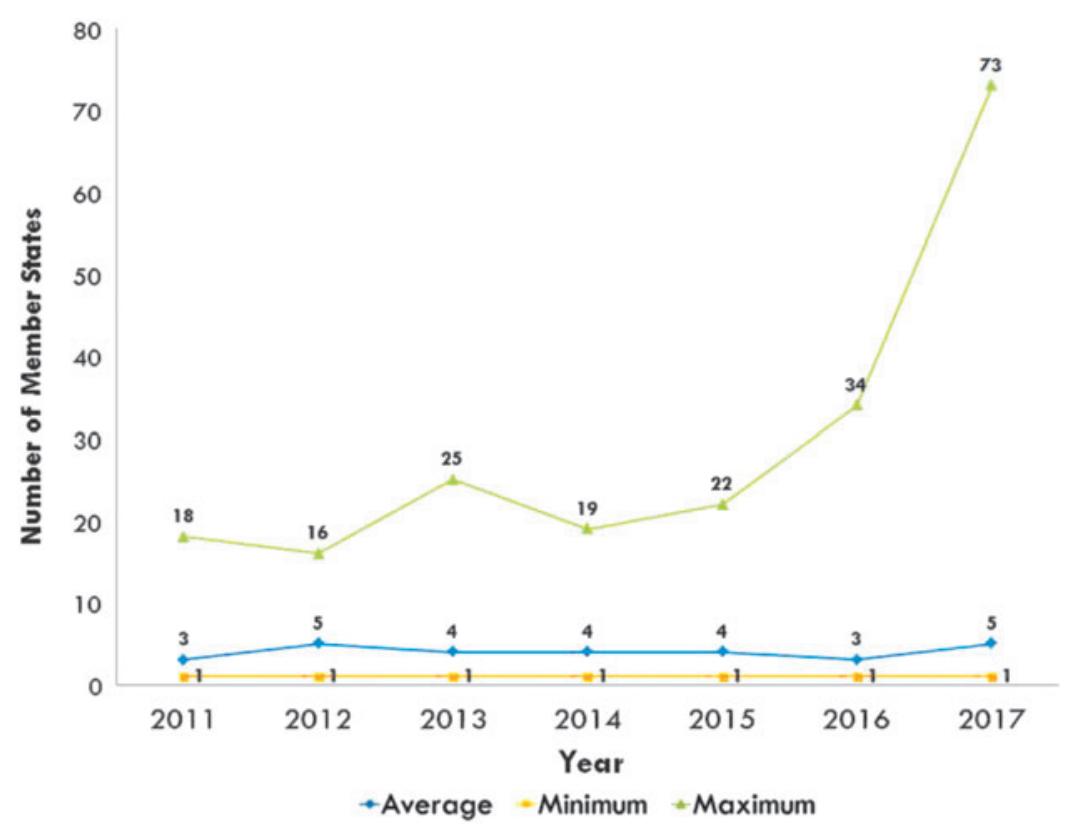

FIG. 1. Average number of Member States involved in each food safety event communicated through INFOSAN, 20112017. Each food safety event communicated through INFOSAN between 2011 and 2017 has involved an average of four Member States with a minimum of 1 and a maximum of 73. INFOSAN, International Food Safety Authorities Network. 


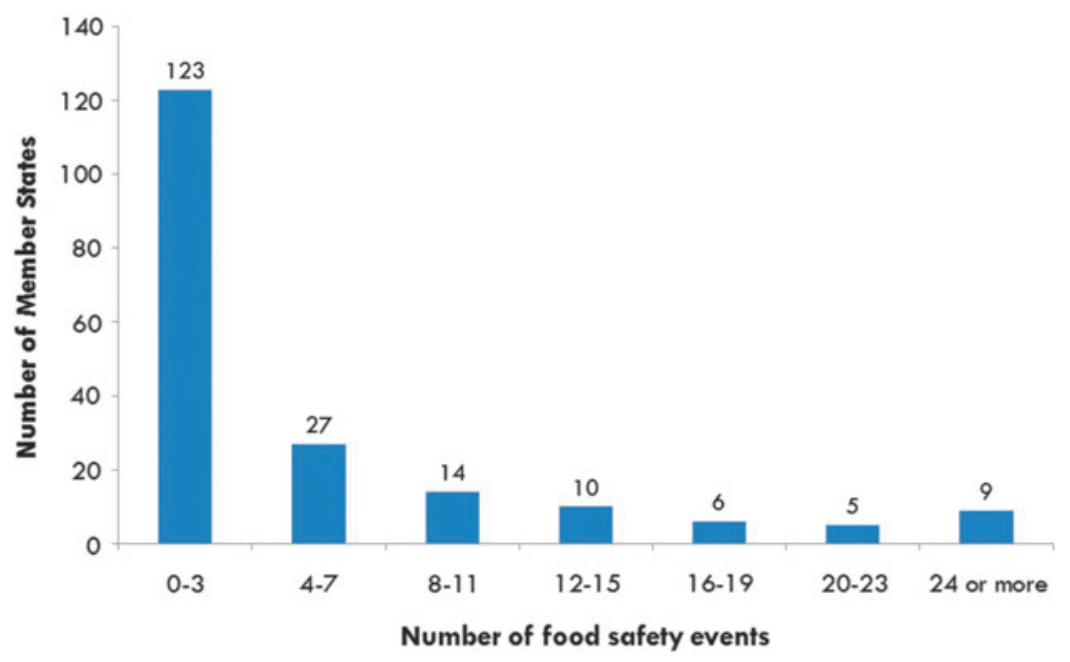

FIG. 2. Member State involvement in food safety events communicated through INFOSAN, 2011-2017. Between 2011 and 2017, 293 food safety events were communicated through INFOSAN. The majority of Member States (123/194, 63\%) have been involved in three INFOSAN events or less during this entire period, including 36 of 194 (19\%) that have never been involved in an event. INFOSAN, International Food Safety Authorities Network.

documented in a standardized and systematic way since 2011 , enabling analysis on a variety of variables. Before this, information was not consistently collected or archived.

An average of 42 food safety events communicated through INFOSAN have occurred annually in the 7-year period from 2011 to 2017 (total number of events, $N=293$ ). For this analysis, to be considered involved in a food safety event communicated through INFOSAN, a Member State will have received communication from the INFOSAN Secretariat due to that Member States' production, export, or import of a particular food product, or because of an ongoing outbreak of foodborne disease within its borders.

Each year, an average of 74 of 194 (38\%) Member States have been involved in food safety events communicated through INFOSAN, with a minimum of 56 of 194 (29\%) in 2011 and a maximum of 120 of $194(62 \%)$ in 2017. Before a sharp increase in 2017, the trend was relatively stable, with an average of 66 of 194 (34\%) communicating through INFOSAN each year. Overall, 159 of 194 (82\%) have been involved in a food safety event communicated through INFOSAN between 2011 and 2017 (Table 1) and each event has involved an average of four Member States with a minimum of 1 and maximum of 73 (Fig. 1). However, the majority of Member States have been involved in three events or less during this period $(123 / 194,63 \%)$, including 36 of $194(19 \%)$ that have never been involved in an event (Fig. 2). The Member States most frequently involved in a food safety event communicated through INFOSAN are given in Table 2.

During food safety events, the INFOSAN Secretariat will often request information from INFOSAN Emergency Contact Points after the receipt of information indicating potential international concern. Information requested may relate to the verification of the event, distribution patterns of contaminated food, details on reported cases of foodborne illness, risk management measures implemented, and so on. In such instances, members receiving the request are asked to acknowledge receipt within $24 \mathrm{~h}$ and to respond with the requested information as soon as possible. To understand how responsive INFOSAN members have been, data from
459 requests for information relating to 192 food safety events between 2011 and 2017 have been analyzed.

Three measures of responsiveness have been examined: the first is whether or not the request for information is acknowledged by the INFOSAN Emergency Contact Point within $24 \mathrm{~h}$; the second is whether or not the request is acknowledged at all; and the third is whether or not the information requested was eventually provided. Figure 3 provides the overall responsiveness including acknowledgements and provision of information. During this 7-year period, overall responsiveness with respect to acknowledgements increased relatively steadily, from a minimum of $28 \%$ in $2011(25 \%$ within $24 \mathrm{~h}$ ) to a maximum of $91 \%$ in 2017 (59\% within $24 \mathrm{~h}$ ).

A clear trend is less apparent with respect to the actual provision of the information requested by the INFOSAN Secretariat from the INFOSAN Emergency Contact Points: during the 7-year period, 70\% (318/459) of all requests made

\begin{tabular}{|c|c|}
\hline Member state & $\begin{array}{c}\text { No. of events } M S \text { was } \\
\text { involved in }(\mathrm{N}=293) \\
\mathrm{n}(\%)\end{array}$ \\
\hline (1) United States & $91(31)$ \\
\hline $\begin{array}{l}\text { (2) China (including } \mathrm{HK} \\
\text { and Macao) }\end{array}$ & $64(22)$ \\
\hline (3) Canada & $60(20)$ \\
\hline (4) Australia & 48 (16) \\
\hline (5) United Kingdom & $48(26)$ \\
\hline (6) France & 40 (14) \\
\hline (7) Germany & 40 (14) \\
\hline (8) The Netherlands & 36 (12) \\
\hline (9) New Zealand & $25(9)$ \\
\hline 10) Italy & $22(8)$ \\
\hline 10) Singapore & $22(8)$ \\
\hline
\end{tabular}

MS, Member States. 


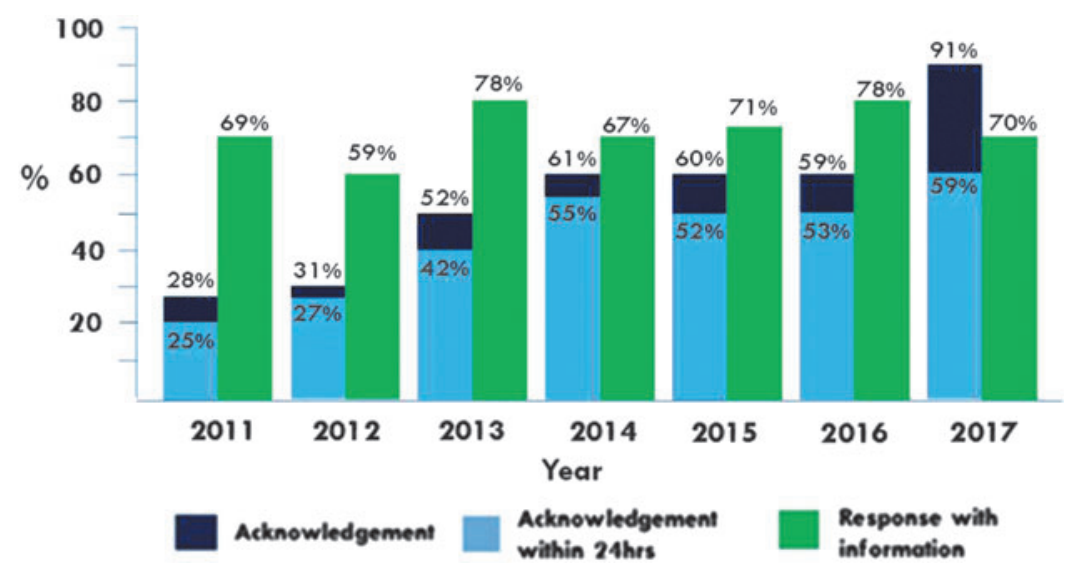

FIG. 3. Overall responsiveness of INFOSAN members to requests for information from the INFOSAN Secretariat during international food safety events, 2011-2017. To understand how responsive INFOSAN members have been, data from 459 requests for information relating to 192 food safety events between 2011 and 2017 have been analyzed. INFOSAN, International Food Safety Authorities Network.

to INFOSAN Emergency Contact Points were answered with the provision of information (with a low of 59\% in 2012 and high of 78\% in 2013 and 2016). The average number of days it took for information requests to be acknowledged between 2011 and 2017 is two and the average number of days it took for information to be provided following an information request between 2011 and 2017 is seven. During this period, differences in responsiveness have been observed between different regions with members from the Americas, SouthEast Asia, the Western Pacific, and Europe demonstrating the most responsive behavior than those from the Eastern Mediterranean and Africa (Table 3).

\section{Learning from the Past: Potential Barriers to Active Participation in INFOSAN}

The above analysis of emergency communication provides an indication that active participation in INFOSAN during food safety events is somewhat limited to a core group of Member States. Important to note is that involvement of a Member State in food safety events communicated through INFOSAN should not be equated with an unsafe national food supply. Rather, on the contrary, active participation in INFOSAN may perhaps signal those Member States that have prioritized food safety and/or open and transparent in- formation exchange to facilitate recalls of contaminated products and limiting disruption to food import and export.

Active participation in INFOSAN may also indicate those well-resourced Member States with robust food control systems and sensitive and effective surveillance tools in place that allow for the identification of foodborne illness and unsafe food, as well as the protocols to facilitate their reporting at the international level.

Although these potential explanations remain hypotheses and require further exploration, they may also suggest a relationship between the frequency of Member State involvement in food safety events communicated through INFOSAN and Gross Domestic Product (GDP) (World Bank, 2018a), value of food product exports (USD) (World Bank, 2018b), and value of food product imports (USD) (World Bank, 2018c). Indeed, when the Pearson product-moment correlation coefficient is computed to assess the association between frequency of Member State involvement in food safety events communicated through INFOSAN (2011-2017) and each of the aforementioned three variables, there is a strong and positive correlation with each (Table 4).

For INFOSAN to truly reach its full potential, commitment to timely and active engagement from the full membership should be strived for. The fact that information requests have, on average, taken $7 \mathrm{~d}$ to respond to, leaves much room for

Table 3. Regional Differences in Responsiveness (Acknowledgement of Requests and Provision of Information Requested by the International Food Safety Authorities Network Secretariat During Food SAfety Events, $N=459), 2011-2017$

\begin{tabular}{|c|c|c|c|}
\hline $\begin{array}{l}\text { Region (No. of events } \\
\text { from } 2011 \text { to 2017) }\end{array}$ & $\begin{array}{c}\text { No. of events for which } \\
\text { acknowledgement of request } \\
\text { for information was provided } \\
\text { at any time (\%) }\end{array}$ & $\begin{array}{l}\text { No. of events for which } \\
\text { acknowledgement of request } \\
\text { for information was } \\
\text { provided with } 24 \mathrm{~h}(\%)\end{array}$ & $\begin{array}{l}\text { No. of events for which } \\
\text { requested information } \\
\text { was provided }(\%)\end{array}$ \\
\hline Africa (22) & $12(55)$ & $8(36)$ & 7 (32) \\
\hline Americas (124) & $85(69)$ & $78(63)$ & $97(78)$ \\
\hline Eastern Mediterranean (15) & 7 (47) & $3(20)$ & $6(40)$ \\
\hline Europe (146) & $61(42)$ & $45(31)$ & $99(68)$ \\
\hline South-East Asia (27) & $18(67)$ & $14(52)$ & $19(70)$ \\
\hline Western Pacific (125) & $70(56)$ & $58(46)$ & $90(72)$ \\
\hline All regions (459) & $253(55)$ & $206(45)$ & $318(69)$ \\
\hline
\end{tabular}


Table 4. Pearson's Product-Moment Correlations for Frequency of Member State Involvement in Food Safety Events Communicated Through the International Food Safety Authorities Network (2011-2017) and Gross Domestic Product in United States Dollars (2017), Value of Food Product Exports (USD; 2016) and Value of Food Product Imports (USD; 2016)

\begin{tabular}{lccc}
\hline & $\begin{array}{c}\text { GDP USD } \\
(2017)\end{array}$ & $\begin{array}{c}\text { Value of food product } \\
\text { exports USD (2016) }\end{array}$ & $\begin{array}{c}\text { Food product } \\
\text { imports USD (2017) }\end{array}$ \\
\hline $\begin{array}{l}\text { Frequency of MS involvement } \\
\text { in events communicated through } \\
\text { INFOSAN 2011-2017 }\end{array}$ & $0.7818^{\mathrm{a}}$ & $0.9203^{\mathrm{b}}$ & $0.8191^{\mathrm{c}}$ \\
\hline
\end{tabular}

$p<0.0001$ for all values, significance level at 0.01 .

${ }^{\mathrm{a}} N=184 ;{ }^{\mathrm{b}} N=192 ;{ }^{\mathrm{c}} N=191$.

GDP, Gross Domestic Product; INFOSAN, International Food Safety Authorities Network, MS, Member States.

improvement if INFOSAN is to function efficiently to halt the international spread of illness caused by contaminated food.

Experience from practice and an applied review of evidence conducted by the INFOSAN Secretariat in collaboration with the Geneva Graduate Institute of International and Development Studies in 2014, has illuminated a number of potential barriers to active participation in INFOSAN (Savelli, 2014). These barriers have been divided into national-level barriers, that is, those that need to be addressed by individual Member States, and international-level barriers, that is, those that require action from the INFOSAN Secretariat or from the global community of INFOSAN members as a whole (Table 5). The obtainment of structured feedback from INFOSAN members on the relative importance of these barriers and potential solutions to overcome them should be considered.

\section{Looking to the Future}

Although INFOSAN has been operating for nearly 15 years to facilitate the aforementioned activities among its members, a number of challenges and limitations have been identified, specifically with respect to the responsiveness of INFOSAN members during international food safety emergencies. As the majority of members may go years between involvement in food safety events communicated through INFOSAN, efforts to engage these members and bolster preparedness should be considered to ensure that when they do become involved, they are ready to respond rapidly. As in past years, attendance to capacity-building INFOSAN workshops, meetings, webinars, and other training opportunities, including participation in simulation exercises will be encouraged for such members.

In addition, INFOSAN has never been characterized or examined as a functional $\mathrm{CoP}$ and its value, as understood from the perspective of its members, has never been determined in a systematic or rigorous way. INFOSAN operations could be optimized if there was a clear understanding of its stage of community development (Wenger et al., 2002), taking into account its structuring characteristics (Dube et al., 2006).

In the future, INFOSAN would benefit from further exploration into the experiences of members with respect to their participation in Network activities as a means to enhance active participation and improve global food safety and prevent foodborne illness. Specifically, this could be achieved by first examining the ICW to characterize membership and understand members' patterns of access, usage, and contribution. In addition, efforts should be made to gain a broad and deep understanding of the barriers and enablers to

Table 5. Potential Barriers to Active Participation in the International Food Safety Authorities Network at National and InTERnational LeVElS

\footnotetext{
National level

Capacity related: limited capacity/infrastructure dedicated to addressing foods safety

Insufficient funds: human resources/expertise; national food control system underdeveloped

Training related: laboratory analysis; food safety risk assessment; outbreak investigation

Standardization: no standardized information sharing at national level

Coordination: lack of coordination among national authorities

Legal constraints: legal implications hinder prompt information sharing; lack of food safety legislation; lack of cooperation from industry

Political constraints: food safety not prioritized

Negative impact to economy: trade; tourism

International level

Unclear mandate: need to better understand role and or services of INFOSAN Secretariat

Unclear roles and responsibilities: need to clarify expectations for members

Lack of standardization: data/information requests

Language: most correspondence is only in English

Timeliness: information reported to and from secretariat needs to be timely

Accuracy of information: concerns for data accuracy; precautionary versus confirmed

Trust: lack of trust between authorities outside own country; unknown repercussions

Confidentiality: fears that confidentiality will not be respected
}

INFOSAN, International Food Safety Authorities Network. 
active participation in INFOSAN to prioritize interventions by the Secretariat to improve engagement. Furthermore, members' perceptions should be elicited in a rigorous way with respect to the utility of INFOSAN as a global communication tool for KTE and the prevention of foodborne illness in each respective country. In this way, the Secretariat shall be able to determine how participation in INFOSAN might create value for members and explore the mechanisms through which this may occur.

\section{Conclusion}

Over the past 15 years, INFOSAN has grown into a truly global network with a global mandate, endorsed by 194 Member States of the WHO. In addition, the entrenchment of INFOSAN within the IHR (2005) framework, and within important CAC guidelines, provides further acknowledgement and support for the need for such a network and its global importance. Perhaps most importantly, INFOSAN has demonstrated its utility in numerous global food safety emergencies, including the recent outbreak of listeriosis linked to internationally distributed ready-to-eat meat from South Africa and the outbreak of salmonellosis among infants in France linked to internationally distributed infant formula (WHO, 2018b).

Maintaining functional links to other regional and global networks remains an important priority for INFOSAN. In a complex global landscape, INFOSAN has emerged as the only network of its kind with a truly global mandate to connect food safety authorities around the world for the purpose of exchanging information during food safety emergencies. However, INFOSAN does not function without limitations. Active participation among a broader base of members and the timeliness of requests for information could be improved. Next steps will include further research to explore the experiences of members and thoroughly define the interlinkages between INFOSAN and other regional and global initiatives that could highlight the specific areas in which to introduce operational shifts by the INFOSAN Secretariat. In turn, this may increase the value of active participation among INFOSAN members, eliminating barriers to participation, and leading to a stronger global CoP and a robust and meaningful impact at country level to reduce the burden of foodborne disease globally.

\section{Disclosure Statement}

No competing financial interests exist.

\section{References}

Dube L, Bourhis A, Jacob R. Towards a typology of virtual communities of practice. Interdiscip $\mathrm{J}$ Inform Knowledge Manage 2006;1:69-93.

European Commission. RASFF WI 3.2: Rules on Informing INFOSAN. 2017. Available at: https://ec.europa.eu/food/sites/ food/files/safety/docs/rasff_reg-guid_sops_2018_wi-3-2_en .pdf, accessed November 30, 2018.

FAO/WHO. FAO/WHO Global Forum of Food Safety Regulators Marrakesh, Morocco, January 28-30, 2002. Proceedings of the Forum. 2002a. Available at: www.fao.org/docrep/ meeting/004/y3680e/Y3680E00.htm, accessed November 30, 2018.
FAO/WHO. FAO/WHO Pan-European Conference on Food Safety and Quality. Final Report. 2002b. Available at: www .fao.org/3/a-y3696e.pdf, accessed November 30, 2018.

FAO/WHO. Principles and Guidelines for the Exchange of Information in Food Safety Emergency Situations (CAC/GL 19-1995) Rev-1 2004. 2004a. Available at: www.fao.org/ docrep/009/y6396e/Y6396E07.htm, accessed November 30, 2018.

FAO/WHO. FAO/WHO Second Global Forum for Food Safety Regulators in 2004. Proceedings of the Forum. 2004b. Available at: www.fao.org/3/a-y5871e.pdf, accessed November 30, 2018.

FAO/WHO. Second International Conference on Nutrition. Conference Outcome Document: Framework for Action. 2014. Available at: www.fao.org/3/a-mm215e.pdf, accessed November 30, 2018.

FAO/WHO. INFOSAN Activity Report 2014/2015. 2016a. Available at: http://apps.who.int/iris/bitstream/10665/246204/ 1/9789241510592-eng.pdf, accessed November 30, 2018.

FAO/WHO. Principles and Guidelines for the Exchange of Information in Food Safety Emergency Situations (CAC/GL 19-1995) Rev-2 2016. 2016b. Available at: www.fao.org/ fao-who-codexalimentarius/sh-proxy/fr/?nk=1\&url=https\% $253 \mathrm{~A} \% 252 \mathrm{~F} \% 252 \mathrm{Fw}$ orkspace.fao.org $\% 252 \mathrm{Fsites} \% 252 \mathrm{~F}$ codex $\% 252 \mathrm{FStandards} \% 252 \mathrm{FCAC} \% 2 \mathrm{BGL} \% 2 \mathrm{~B} 19-1995 \%$ 252FCXG_019e.pdf, accessed November 30, 2018.

Gossner C, Schlundt J, Ben Embarek P, Hird S, Lo-Fo-Wong D, Beltran $\mathrm{J}$, et al. The melamine incident: Implications for international food and feed safety. Environ Health Perspect 2009; 117:1803-1808.

Nadon C, Van Walle I, Gerner-Smidt P, Campos J, Chinen I, Concepcion-Acevedo J. et al. PulseNet International: Vision for the implementation of whole genome sequencing (WGS) for global food-borne disease surveillance. Eurosurveillance 2017;22:30544. DOI: 10.2807/1560-7917.es.2017.22 .23 .30544 .

Nanyang Technological University. Report of the INFOSAN Meeting on Regional Perspectives of Food Science Developments in Asia. 2016. Available at: www.slideshare.net/ LeeGheeSeow/new-science-for-food-safety-supporting-foodchain-transparency-for-improved-health-75462556, accessed November 30, 2018.

Savelli C. Investigating Barriers and Best Practices for Intersectoral Collaboration and Active Participation in the FAO/ WHO International Food Safety Authorities Network (INFOSAN). 2014. Available at: www.lcirah.ac.uk/sites/default/ files/LCIRAH\%20SAVELLI.pdf, accessed November 30, 2018.

Wenger E, McDermott R, Snyder W. Cultivating Communities of Practice. Boston, MA: Harvard Business School Press, 2002.

WHO. Resolution WHA53.15 Food Safety. 2000. Available at: http://apps.who.int/gb/archive/pdf_files/WHA53/ResWHA53/ 15.pdf, accessed November 30, 2018.

WHO. Resolution WHA55.16 Global Public Health Response to Natural Occurrence, Accidental Release or Deliberate Use of Biological and Chemical Agents or Radionuclear Material That Affect Health. 2002. Available at: http://apps.who.int/ gb/archive/pdf_files/WHA55/ewha5516.pdf, accessed November 30, 2018.

WHO. Terrorist Threats to Food: Guidance for Establishing and Strengthening Prevention and Response Systems. 2003. Available at: http://apps.who.int/iris/handle/10665/42619, accessed November 30, 2018.

WHO. Advancing Food Safety Initiative: Strategic Plan for Food Safety Including Foodborne Zoonoses 2013-2022. 
2014. Available at: www.who.int/foodsafety/publications/ strategic-plan/en, accessed November 30, 2018.

WHO. Global Burden of Foodborne Disease Report. 2015. Available at: http://apps.who.int/iris/bitstream/10665/200046/ 1/WHO_FOS_15.02_eng.pdf?ua=1, accessed November 30, 2018.

WHO. Joint External Evaluation Tool, Second Edition. 2018a. Available at: http://apps.who.int/iris/bitstream/handle/10665/ 259961/9789241550222-eng.pdf?sequence $=1$, accessed November 30, 2018.

WHO. INFOSAN Quarterly Summary (January-March 2018). 2018b. Available at: www.who.int/foodsafety/areas_work/ infosan/INFOSAN-QS/en, accessed November 30, 2018.

World Bank. GDP (Current US\$). 2018a. Available at: https:// data.worldbank.org/indicator/NY.GDP.MKTP.CD? accessed November 30, 2018.

World Bank. World Food Products Export by Country and Region 2016. 2018b. Available at: https://wits.worldbank
.org/CountryProfile/en/Country/WLD/Year/2016/TradeFlow/ Export/Partner/by-country/Product/16-24_FoodProd, accessed November 30, 2018.

World Bank. World Food Products Imports by Country and Region 2016. 2018c. Available at: https://wits.worldbank .org/CountryProfile/en/Country/WLD/Year/2016/TradeFlow/ Import/Partner/all/Product/16-24_FoodProd, accessed November 30, 2018.

Address correspondence to: Carmen Joseph Savelli, BSc, MPH Department of Food Safety and Zoonoses World Health Organization Avenue Appia 20 1211 Geneva Switzerland

E-mail: savellic@who.int 